\title{
Comparison of capsule type resin modified glass ionomer porosity according to mixing methods
}

\author{
Jung-min Kim, Jin-Woo Kim, Kyung-Mo Cho, Yoon Lee, Eung-Hyun Kim, Se-Hee Park* \\ Department of Conservative Dentistry, College of Dentistry, Gangneung-Wonju National University, Gangneung, Republic of Korea
}

Purpose: The purpose of this study was to evaluate the porosity of resin modified glass ionomer (RMGI) by different mixing methods. Materials and Methods: Five specimens were prepared for each groups according to capsules and mixing methods. Two RMGI capsule and two mixing machines were used for this study. One resin-modified glass ionomer cement is Fuji II LC (F2LC) and the other is Photac Fil Quick Aplicap (PFQ). For Mixing of RMGI capsule, Rotomix using rotating motion and CM-II using shaking motion were used. After measuring height, radius and mass of specimens, Density was calculated. And porosity was measured using micro-computed tomography (micro-CT). All data were statistically analyzed using T-test, two-way ANOVA to compare between groups at $95 \%$ significance level to evaluate the affect of capsule and mixing method on the porosity. Results: The porosity was observed in all specimens generally. And there is significant differece between porosities according to RMGI capsule and Mixing method. The porosity of PFQ was lower than that of F2LC and the porosity of Rotomix was lower than that of CM-II. Conclusion: There was a difference of porosity according to kind of capsules and mixing methods. When using same capsule, less porosity was observed on PFQ than F2LC. When using same mixing mehod, less porosity was observed on Rotomix than CM-II. Using mixing machine of same coporation as that of RMGI capsule did not lead to lower porosity. Therefore, Selecting optimal mixing machine is important. (J Dent Rehabil Appl Sci 2021;37(4):217-24)

Key words: capsule; density; micro-CT; mixing method; porosity; resin modified glass iononer (RMGI)

\begin{abstract}
서론
Resin modified glass ionomer (RMGI)는 기존의 glass-ionomer의 성분(glass powder, water, and polyacid) 에 레진 성분(monomer, initiator system)이 포함되어 있 다. 이 재료는 부분적으로는 산-염기 반응에 의해서, 부 분적으로는 광중합에 의해서 경화 반응이 일어난다. 이 러한 개선을 통해 연장된 작업시간과 빨라진 경화시간, 낮아진 수분 민감성, 향상된 기계적 강도를 지녀 재래형 글라스 아이오노머보다 사용이 쉽고 더 넓은 적용 범위 를 지닌다. ${ }^{1}$
\end{abstract}

Powder와 liquid로 구성된 Resin modified glass ionomer (RMGI)는 powder와 liquid를 수동으로 혼합하거 나 캡슐형을 기계로 혼합하여 사용할 수 있다. 수동으로 혼합하는 경우 scoop을 채우는 powder의 밀도나 liquid 를 떨어뜨릴 때의 양에 따라 powder와 liquid의 비율(PL ratio)이 달라지게 되며, 혼합을 하는 사람에 따라 그 특 성이 달라질 수 있다. ${ }^{2}$ 이러한 단점을 보완하고자 최근에 는 캡슐형 RMGI가 많이 사용되고 있다. 캡슐형 RMGI 의 경우 정해진 powder/liquid 비율로 준비되어 있고, 기 계적으로 일정하게 혼합할 수 있어 재료의 특성을 표준 화 시킬 수 있고 혼합하는 사람에 따라 차이가 유발되는
*Correspondence to: Se-Hee Park
Professor, Department of Conservative Dentistry, College of Dentistry, Gangneung-Wonju National University, 7, Jukheon-gil, Gangneung, 25457, Republic of Korea

Tel: +82-33-640-2760, Fax: +82-33-640-3103, E-mail: drendo@gwnu.ac.kr Received: October 16, 2021/Last Revision: October 29, 2021/Accepted: November 9, 2021 
것을 줄일 수 있다는 장점이 있다. ${ }^{3}$

모든 치과용 수복재는 혼합과정에서 기포가 발생할 수 있으며, 이러한 기포가 구강 내에 노출되면 기계적 실패 (mechanical failure)를 유발할 가능성이 높다. ${ }^{4}$ 수복물의 표면에 포함된 기포가 구강 내 용액에 노출되면 수복물 의 용해를 가속화 시킬 수 있으며, 빛의 파장보다 큰 직경 의 기포는 투명도를 낮추고, 추후 착색되어 심미성을 훼 손하게 된다. ${ }^{5}$ 또한 기포는 응력집중 지점이 되고, 재료의 취성을 높일 수 있다. ${ }^{6}$ 이러한 이유로 낮은 응력하에서의 파절은 주로 큰 기포가 있는 곳에서 발생한다. ${ }^{3} 10 \%$ 의 공극률이 전체적인 강도를 $50 \%$ 까지 감소시킬 수 있다고 한 바 있고, ${ }^{7}$ 공극률을 포함한 기계적 특성은 여러 혼합 방식에 따라 달라질 수 있으며, 이는 수복물의 장기적 예 후에 영향을 미칠 수 있다. ${ }^{7,8}$

캡슐 혼합기는 제조사별로 다양하며, 혼합 방식이나 각 기계로 혼합된 재료의 특성도 다양한 차이를 보일 수 있다. 지금까지 캡슐형 RMGI를 기계로 혼합했을 때와 수동으로 혼합하였을 때 포함된 기포의 양이나 물리적 특성을 비교하는 몇 편의 연구가 있었지만 혼합기계별로 캡슐형 RMGI의 공극률이나 기계적 특성을 비교하는 연 구는 전무하다. 따라서 본 연구에서는 기계적 혼합 방식 에 따른 시편의 공극률을 micro-computed tomography (micro-CT)를 통해 비교하고자 한다.

\section{연구 재료 및 방법}

이번 연구를 위해 2가지 종류의 RMGI 캡슐을 사용하 였다. RMGI 캡슐로는 Photac Fil Quick Aplicap (PFQ, 3M ESPE, Seefeld, Germany)과 Fuji II LC CASULE (F2LC, GC Co., Tokyo, Japan)을 사용하였다. 각 캡슐 의 구성성분은 Table 1 에 나타내었으며, 각 캡슐의 구조
를 x-ray를 이용하여 촬영한 사진은 Fig. 1 에 나타내었다. 치과용 수복재 중 $0 \%$ 나 고정된 공극률을 가지는 재료는 존재하지 않기 때문에 따로 대조군은 설정하지 않았으 며, ${ }^{9}$ 실험군들 간의 공극률 비교만을 시행하였다.

모든 재료는 제조자의 지시에 따라 사용하였다. 캡슐 화된 RMGI는 Rotating 방식을 사용하는 RotoMix (3M $\mathrm{ESPE}$ )와 shaking 방식을 사용하는 CM-II (GC Co.)로 혼합하였다. ${ }^{3}$ 각 Mixer의 특징은 Table 2에 나타내었다. 공극률을 측정하기 위한 시편을 제작하기 위해 평가방법 은 ISO Specifications 9917-1:2007에 의한 기준에 의하 여 설계하였다. ${ }^{10}$ 공극률의 측정을 위해 스테인리스 틀을 이용하여 직경 $6 \mathrm{~mm}$, 높이 $3 \mathrm{~mm}$ 인 시편을 제작하였다 (Fig. 2).

공극률을 평가하기 위해 2가지 RMGI 캡슐을 2가지 다른 혼합기계로 나눠 시편을 각각 5 개씩 총 20 개를 제 작하였다. 각각의 캡슐은 제조사의 지시에 따라 혼합하 였다. 스테인리스 틀을 유리판 위에 올려두고, 밑면은 mylar strip으로 덮었다. 그 후 혼합이 끝난 각 캡슐을 주 형에 살짝 과충전하는데, 이때 캡슐의 노즐이 주형의 벽

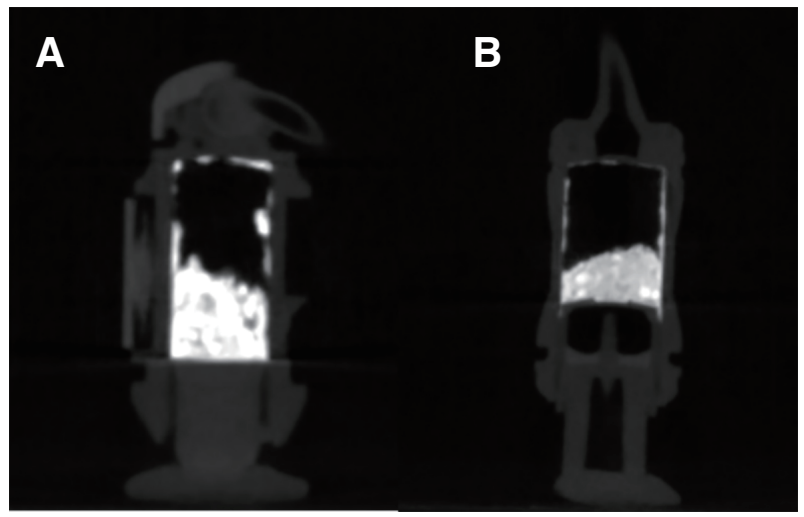

Fig. 1. Configuration of casule. (A) PFQ, (B) F2LC.

Table 1. Compositon of RMGI capsules used in this study

\begin{tabular}{ccccc}
\hline $\begin{array}{c}\text { Material } \\
\text { code }\end{array}$ & Product name & Type of material & Manufacturer & Composition \\
\hline PFQ & $\begin{array}{c}\text { Phorac Fil } \\
\text { Quick Aplicap }\end{array}$ & $\begin{array}{c}\text { Resin-modified } \\
\text { GIC, Visible light- } \\
\text { cured, Restorative }\end{array}$ & $\begin{array}{c}\text { 3M, Seefeld, } \\
\text { Germany }\end{array}$ & $\begin{array}{c}\text { Liquid: glass ionomer compatible monomers and } \\
\text { oligomers, acrylic- and maleic-acid copolymers; } \\
\text { camphoroquinone; stabilizers; water/ }\end{array}$ \\
F2LC & Fuji II LC & $\begin{array}{c}\text { Resin-modified } \\
\text { GIC, Visible light- } \\
\text { cured, Restorative }\end{array}$ & $\begin{array}{c}\text { GC Corporation, } \\
\text { Tokyo, Japan }\end{array}$ & $\begin{array}{c}\text { Liquid: polyacrylic acid; HEMA; } 2,2,4 \\
\text { TMHEDC; TEGDMA }\end{array}$ \\
Powder: fluoro-alumino-silicate glass
\end{tabular}

Data from manufacturers's websites and/or product catalogs. 
Table 2. Feature of the mixers used in this study

\begin{tabular}{clc}
\hline Mixer & Mixing speed & \\
\hline \multirow{2}{*}{ RotoMix } & Size & $(\mathrm{w} \times \mathrm{H} \times \mathrm{D}) 180 \times 210 \times 250 \mathrm{~mm}$ \\
& Weight & $4 \mathrm{~kg}$ \\
& Mixing time & $15 \mathrm{~s}($ centrifuge $3 \mathrm{~s})$ \\
& Mixing speed & $4000 \mathrm{rpm}$ \\
& Size & Device: $(\mathrm{w} \times \mathrm{L} \times \mathrm{H}) 190 \times 18 \times 150 \mathrm{~mm}$ \\
CM-II & Weight & Adapter: $(\mathrm{w} \times \mathrm{L} \times \mathrm{H}) 60 \times 120 \times 40 \mathrm{~mm}$ \\
& Mixing time & $2.9 \mathrm{~kg}$ \\
& & $10 \mathrm{~s}$ \\
\hline
\end{tabular}

Data from manufacturers's websites and/or product catalogs.

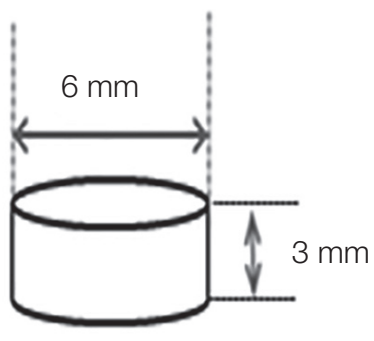

Fig. 2. Testing specimens for porosity measurement.

에 닿게 한 다음 벽을 따라 천천히 올리며 채우도록 주의 하였다. 과도한 RMGI를 제거하고 바닥과 평행의 편평 한 표면을 얻기 위해 mylar strip으로 덮은 뒤 유리판으 로 눌러주었으며, 각 주형의 위, 아래를 G-Light $(1,200$ $\mathrm{mW} / \mathrm{cm}^{2}$, continuous mode, GC Co.)로 각각 20초씩 광중합한 뒤, 시편을 주형으로부터 분리하였다. ${ }^{11}$ 각 시 편의 높이를 포인트 마이크로미터(Point micrometer 103, Mitutoyo, Kawasaki, Japan)로 측정하고, 시편의 높이에서 $1 / 2$ 지점의 원주를 실을 이용하여 측정하여 그 반지름을 구하였다. 그 후 전자저울(CAW 220, CAS corporation, Yangju, Korea)로 질량을 측정하여 밀도(질 량/부피, $\mathrm{g} / \mathrm{cm}^{3}$ )를 구하였다.

각 시편은 micro-CT ( $\mu$ CT 45, SCANCO Medical $\mathrm{AG}$, Bruttisellen, Swiss)를 이용하여 촬영하였다. X-ray generator는 $90 \mathrm{kV}, 44 \mu \mathrm{A}$ 로 작동되었다. 시편의 장축을 따라 470 개의 슬라이스를 지면과 평행하게 얻은 뒤, $\mu \mathrm{CT}$ Evaluation Program V6.6 (SCANCO Medical AG)으로 기포의 크기 기준을 설정한 뒤, 범위에 속하는 시편 내의 모든 공극을 Fig. 3 와 같이 $3 \mathrm{D}$ 로 재구성한 다음 동일한

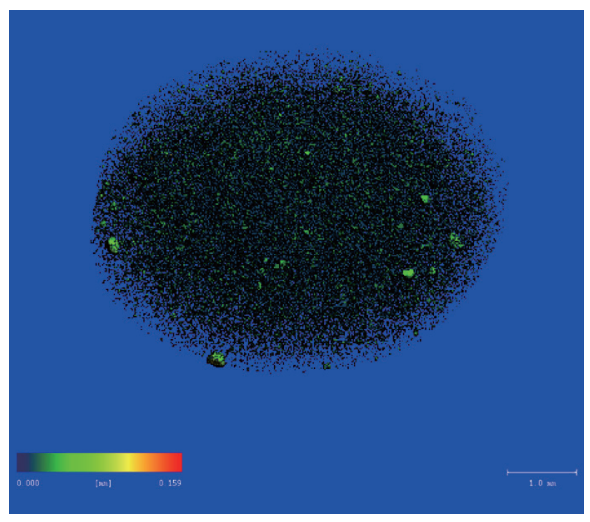

Fig. 3. 3D reconstruction of empty space of specimen.

소프트웨어 프로그램으로 내부의 공극률을 측정하였다. Micro-CT로 분석했을 때 거의 모든 수복재에서 대부분 의 기포가 $0.1-18 \mu \mathrm{m}$ 범위에 존재하였으며, ${ }^{12} 1 \mu \mathrm{m}$ 이하 의 기포는 재료의 기계적 특성에 영향을 미치지 않기 때 문에 공극률의 분석에서 $1 \mu \mathrm{m}$ 이상의 기포만 포함하였 다. ${ }^{5,11}$

광중합글라스아이노머 캡슐의 종류와 혼합방법이 밀 도와 공극률에 미치는 영향을 평가하기 위하여 이원배 치 분산분석(Two-way ANOVA)을 하였고, 각각의 광 중합글라스아이노머 캡슐에서 혼합방법에 따른 밀도 와 공극률의 유의성을 검증하기 위하여 독립표본 $\mathrm{t}$ 검정 (Independent t-test)을 하였다. 마찬가지로 동일한 혼 합방법에서 광중합글라스아이노머 캡슐의 종류에 따 른 밀도와 공극률의 유의성을 검증하기 위하여 독립표 본 t 검정을 시행하였다. 모든 통계분석은 $95 \%$ 유의수 준에서 진행하였으며, IBM SPSS Statics Ver 25.0 (IBM, Armonk, USA)를 사용하였다. 


\section{결과}

RMGI종류와 혼합방법이 밀도에 미치는 영향에 대한 이원배치 분산분석을 시행하였다. 그 결과를 Table 3에 나타내었다. 분석 결과, 캡슐 종류만이 밀도에 유의한 영 향을 주는 요소로 나타났으며, 혼합방법은 밀도에 유의 한 영향을 주지 않았다. 또한 RMGI캡슐의 종류와 혼합 방법은 상호작용효과가 없는 것으로 나타났다.

각각의 혼합방법에서 RMGI 캡슐 종류에서 나타난 밀도의 평균과 표준편차를 Table 4에 나타내었으며, 독 립표본 $\mathrm{t}$ 검정을 시행하여 각 RMGI 군에서의 혼합방 법에 따른 밀도를 비교한 결과를 Fig. 4에 나타내었다. Rotomix, CM-II 모두에서 PFQ 보다 F2LC로 혼합한 경 우에서 밀도가 유의하게 낮았다.

RMGI 캡슐의 종류와 혼합 방법이 공극률에 미치는 영향에 대한 이원배치 분산분석 결과를 Table 5 에 나타 내었다. 분석 결과, 본 연구에서 캡슐 종류와 혼합방법은 각각 공극률에 유의한 영향을 주는 요소로 나타났으며, 동일한 혼합방법에서는 PFQ 보다는 F2LC에서 공극률 이 높았으며, 동일한 RMGI를 사용했을 때는 Rotomix 보다는 CM-II에서 공극률이 높았다. 하지만, RMGI 캡 슐의 종류와 혼합방법 간에는 상호작용효과가 없는 것 으로 나타났다.

각각의 RMGI 캡슐에서 혼합방법에 따른 공극률의 평 균과 표준편차를 Table 6에 나타내었으며, 독립표본 t검 정을 시행하여 각 RMGI 군에서의 혼합방법에 따른 공 극률과 각 혼합방법에서의 RMGI 캡슐에 따른 공극률 을 비교하였고, 그 결과를 Fig. 5에 나타내었다. F2LC, PFQ 모두에서 Rotomix 보다 CM-II로 혼합한 경우에서 공극률이 유의하게 높았으며, Rotomix, CM-II 모두에서
PFQ 보다 F2LC로 혼합한 경우에서 공극률이 유의하게 높았다.

Micro-CT의 단면을 각 그룹별로 Fig. 6에 나타내었다. Mrico-CT 상으로 봤을 때 모든 시편에 크고, 작은 기포 들이 분포되어 있었으며 기포는 RMGI 시편 전체에 걸쳐 고르게 분포하였다. 동일한 RMGI 캡슐에서 Rotomix보 다는 CM-II에서 크기가 큰 기포가 더 많이 분포하는 것 을 볼 수 있었다.

Table 4. Density of materials [Mean $\left(\mathrm{g} / \mathrm{cm}^{3}\right)$ and St. Dev.]

\begin{tabular}{ccc}
\hline \multirow{2}{*}{ Group } & \multicolumn{2}{c}{ Mean \pm St. Dev. } \\
& Rotomix & CM-II \\
\hline PFQ & $2.90 \pm 0.03$ & $2.87 \pm 0.01$ \\
F2LC & $2.83 \pm 0.04$ & $2.85 \pm 0.03$ \\
\hline
\end{tabular}

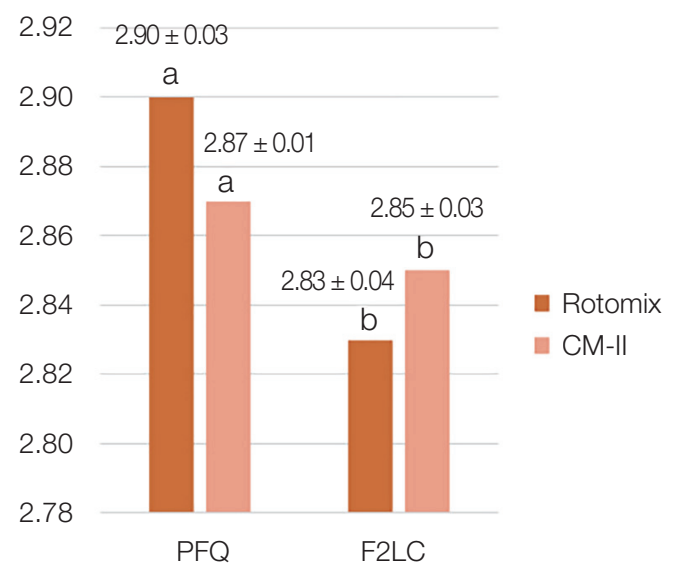

Fig. 4. Result of Two-way ANOVA test on density $\left(\mathrm{g} / \mathrm{cm}^{3}\right)$. *Different alphabet letteres are significant difference $(P$ $<0.05)$.

Table 3. Result of Two-way ANOVA test on density

\begin{tabular}{|c|c|c|c|c|c|}
\hline Source & Sum of squares & $\mathrm{df}$ & Mean square & $\mathrm{F}$ & Sig. \\
\hline Corrected Model & $.017^{\mathrm{a}}$ & 3 & .006 & 7.940 & .002 \\
\hline Intercept & 163.317 & 1 & 163.317 & 235266.930 & .000 \\
\hline Capsule & .015 & 1 & .015 & 20.956 & .000 \\
\hline Mixing method & .001 & 1 & .001 & 1.939 & .183 \\
\hline Capsule*Mixing method & .001 & 1 & .001 & .924 & .351 \\
\hline Error & .011 & 16 & .001 & & \\
\hline Total & 163.345 & 20 & & & \\
\hline Corrected Total & .028 & 19 & & & \\
\hline
\end{tabular}

a. $\mathrm{R}$ square $=.639($ modified $\mathrm{R}$ square $=.523)$. 
Table 5. Result of Two-way ANOVA test on porosity

\begin{tabular}{|c|c|c|c|c|c|}
\hline Source & Sum of squares & $\mathrm{df}$ & Mean square & $\mathrm{F}$ & Sig. \\
\hline Corrected Model & $7.037^{\mathrm{a}}$ & 3 & 2.346 & 26.485 & $<.001$ \\
\hline Intercept & 53.465 & 1 & 53.456 & 603.658 & $<.001$ \\
\hline Casule & 5.387 & 1 & 5.387 & 60.826 & $<.001$ \\
\hline Mixer & 1.602 & 1 & 1.602 & 18.085 & $<.001$ \\
\hline Capsule*Mixer & .048 & 1 & .048 & .542 & .472 \\
\hline Error & 1.417 & 16 & .089 & & \\
\hline Total & 61.919 & 20 & & & \\
\hline Corrected Total & 8.454 & 19 & & & \\
\hline
\end{tabular}

a. $\mathrm{R}$ square $=.832($ modified $\mathrm{R}$ square $=.801)$.

Table 6. Porosity of materials [Mean (\%) and St. Dev.]

\begin{tabular}{ccc}
\hline \multirow{2}{*}{ Group } & \multicolumn{2}{c}{ Mean \pm St. Dev. } \\
& Rotomix & CM-II \\
\hline PFQ & $0.88 \pm 0.14$ & $1.35 \pm 0.30$ \\
F2LC & $1.82 \pm 0.34$ & $2.49 \pm 0.36$ \\
\hline
\end{tabular}

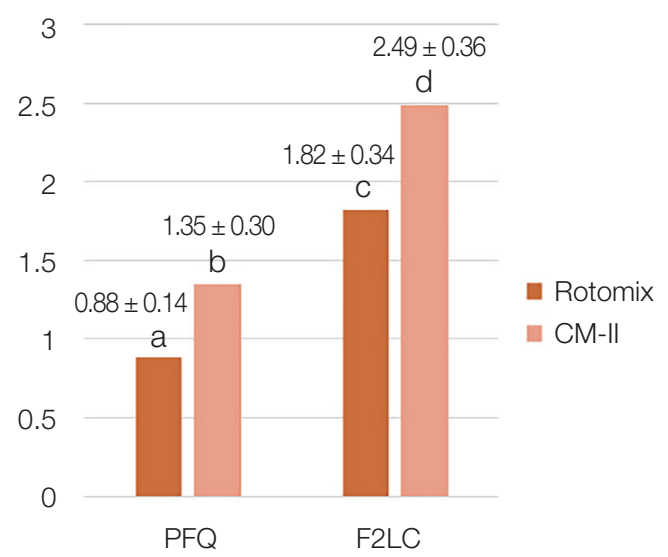

Fig. 5. Result of Two-way ANOVA test on porosity (\%). *Different alphabet letteres are significant difference $(P$ $<0.05)$.

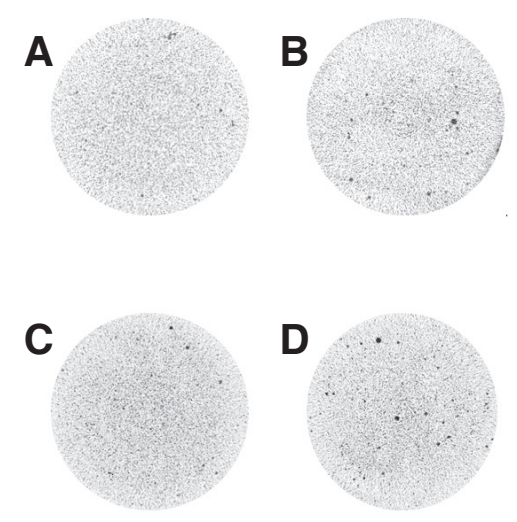

Fig. 6. Porosity of specimens. (A) PFQ + Rotomix, (B) PFQ + CM-II, (C) F2LC + Rotomix, (D) F2LC + CM-II.

\section{고찰}

RMGI는 수동으로 혼합할 수도 있고, 캡슐화하여 기 계적으로 혼합할 수도 있다. 수동으로 혼합하는 경우 파 우더를 덜어낼 때 파우더의 밀도나 액을 떨어뜨리는 양 을 정확하게 하는 것이 어렵기 때문에 PL ratio를 일정하 게 유지하는 것은 매우 어렵다. ${ }^{2}$ Billington 등도 임상에 서 실제 혼합하는 PL ratio의 평균이 제조사 권장비율과 일치하지 않는다고 보고한 바 있다. ${ }^{13}$

그런 이유로 최근에는 캡슐형 RMGI가 많이 쓰이고 있 다. 이전의 다양한 연구들이 캡슐형 RMGI를 기계로 혼 합한 경우와 수동으로 혼합한 경우 다양한 특성들을 비 교한 바 있다. ${ }^{14}$ 하지만 캡슐형 RMGI를 혼합하는 기계 가 회사별로 다양함에도 불구하고 각 혼합기계로 혼합 한 RMGI의 특성을 비교하는 연구는 전무하다. 이에 각 혼합기계별 RMGI의 공극률을 Micro-CT를 이용하여 비교하고자 이번 연구를 기획하게 되었다. Micro-CT는 시편을 자르지 않고도 공극률을 측정할 수 있으며, 외부 와 교통되는 open pore와 재료로 완전히 둘러싸인 close pore를 모두 포함하여 공극률을 측정할 수 있다는 장점 이 있다. ${ }^{15}$

공극률을 포함한 수복재의 기계적 성질은 혼합방법, 혼합속도와 시간 등에 영향을 받는다. ${ }^{16}$ 캡슐형 RMGI를 혼합하는 기계의 일종인 Rotomix와 CM-II의 경우에도 서로 다른 혼합방식, 혼합속도와 혼합시간을 가지고 있 다.

본 연구에서도 두 가지의 서로 다른 운동을 하는 혼합 기계를 사용하여 실험을 진행하였다. 혼합기계별 공극률 (Fig. 5)을 살펴보면 PFQ와 F2LC 모두에서 Rotomix를 사용한 경우에서 CM-II를 사용한 경우보다 공극률이 낮 
았다. Rotomix는 Shaking 방식을 이용하는 기존의 Capmix (3M ESPE)에 비해 rotating 과정에서 생긴 큰 기포 를 centrifuge 과정에서 제거하여 공극률을 줄인다고 하 였다. ${ }^{17} \mathrm{CM}-\mathrm{II}$ 도 Capmix와 마찬가지로 shaking 방식으 로 캡슐을 혼합하기 때문에 Rotomix 보다 더 많은 공극 률을 유발하는 것으로 보인다.

혼합기계별로 혼합속도와 혼합시간 또한 다양하며, 이 또한 공극률에 영향을 미칠 수 있다. 혼합기계의 속도에 따라 글라스아이노머 캡슐의 물리적 특성을 비교한 연구 에서 3500 - $4500 \mathrm{rpm}$ 의 범위에서는 유의한 차이가 없었 지만, $3000 \mathrm{rpm}$ 이하의 저속에서는 물리적 특성의 저하 를 보였다. 이는 낮은 혼합속도는 모든 powder가 liquid 와 혼합하는 데 필요한 충분한 에너지를 전달하지 못하 여 잔여 powder를 남기게 되며, 이는 PL ratio를 낮추기 때문이라고 하였다. ${ }^{18}$ 혼합과정에서 재료에 전달되는 에 너지를 높이기 위해서는 혼합기계의 속도를 높이거나 시 간을 늘리면 된다. ${ }^{19}$

본 실험에서 쓰인 혼합기계별 혼합속도와 시간을 보면, 총 회전수에서 Rotomix $2850 \mathrm{rpm} * 15 / 60$ minute $=713$ 회, CM-II $4000 \mathrm{rpm} * 10 / 60 \mathrm{~s}=667$ 회 로 Rotomix가 CM-II보다 높은 수치를 보인다. 이처럼 Rotomix가 CM-II보다 혼합과정에서 더 높은 에너지를 전달하고 이로 인해 낮은 공극률을 보이는 것으로 생각 된다.

캡슐의 종류에 따라서도 공극률이 달라질 수 있다. 본 실험과 다른 종류의 재료이지만 Glass ionomer (GI)를 rotating과 centrifugal 과정을 포함하는 Rotomix로 혼 합했을 때가 Capmix로 혼합했을 때보다 기포가 적게 나 왔으며, 유의한 차이는 한 가지 재료에서만 나타났다. 이 를 통해 재료의 특성이 혼합과정의 효율성에 영향을 준 다는 것을 알 수 있다. ${ }^{6}$ 본 실험의 캡슐 종류별 밀도(Fig. 4) 와 공극률(Fig. 5)을 살펴보면 Rotomix와 CM-II를 사 용한 경우 모두에서 PFQ 캡슐을 이용한 경우가 F2LC캡 슐을 이용한 경우보다 공극률이 낮았다. 두 제품의 구성 성분을 비교한 표(Table 1)를 보면 두 제품의 구성성분이 완전히 일치하지는 않으며, 두 제품의 밀도가 다른 것을 고려했을 때 그 성분 비율의 차이나 powder의 함량 등에 차이가 있을 것이라 생각된다. 공극률의 차이는 이러한 성분차이에서 비롯된 것으로 생각된다.

캡슐의 종류가 밀도의 차이를 유발한 것에 반해 혼합 방법에 따른 밀도(Fig. 4)는 유의한 차이가 없었다. 같은 캡슐을 사용하였을 때는 제품을 구성하는 성분이 동일하
기 때문에 밀도의 차이를 공극률의 차이로 받아들일 수 있다. 이로써 같은 캡슐을 이용하였을 때 공극률 그 자체 로는 혼합기계별로 유의한 차이가 있었으나(Fig. 4) 밀도 에서 유의한 차이를 유발할만큼 큰 차이는 아니었을 것 으로 생각된다. Fig. 5에서 캡슐의 종류에 따른 공극률의 변화가 혼합방법에 따른 공극룰의 변화보다 큰 것을 알 수 있는데, 이러한 변화 정도의 차이와 성분의 차이 등이 합쳐져 캡슐에 종류에 따라서만 밀도의 유의한 차이가 발생한 것으로 보인다.

Micro-CT상 단면을 봤을 때 모든 시편에 작은 기포가 분포되어 있었으며 기포는 RMGI 시편 전체에 걸쳐 고르 게 분포하였고, 기포의 크기도 다양하였다. 캡슐의 종류 에 관계없이 CM-II를 사용한 경우에서 Rotomix를 사용 한 경우보다 크기가 큰 기포가 많이 발견되었는데(Fig. 6) 이 또한 Rotomix가 혼합과정에서 centrifuge 방식을 통 해 크기가 큰 기포를 제거하기 때문으로 보인다. ${ }^{17}$ 하지 만 본 실험에서 기포의 크기에 따른 공극률을 구체적인 수치로 구하진 못하였다. 그러므로 공극률 뿐 아니라 기 포의 크기 분포, 여러 다른 기계적 특성들에 대한 연구가 추가적으로 필요하다.

\section{결론}

F2LC의 경우 같은 제조회사의 제품인 CM-II를 이용 하여 혼합하는 경우보다 다른 제조회사의 제품인 Roto$\mathrm{mix}$ 를 이용하여 혼합하는 경우에 더 낮은 공극률을 보였 다. 이를 통해 캡슐형 RMGI를 혼합할 때 같은 회사의 제 품을 이용하는 것이 항상 유리한 것은 아니라는 것을 알 수 있으며, 적절한 혼합기계를 선택하는 것이 필요하다. 하지만 본 실험은 공극률에 한정된 비교만을 시행하였기 때문에 다른 물리적 특성에 관한 연구가 더 필요할 것으 로 사료된다.

\section{ORCID}

Jung-Min Kim https://orcid.org/0000-0002-4302-3806 Jin-Woo Kim https://orcid.org/0000-0002-0004-0710 Kyung-Mo Cho https://orcid.org/0000-0003-3464-9425 Yoon Lee https://orcid.org/0000-0001-9813-8531

Eung-Hyun Kim https://orcid.org/0000-0002-2251-1691 Se-Hee Park https://orcid.org/0000-0002-4052-4082 


\section{References}

1. Nicholson JW, Sidhu SK, Czarnecka B. Enhancing the mechanical properties of glass-ionomer dental cements: a review. Materials 2020;13:2510.

2. Al-Taee L, Deb S, Banerjee A. An in vitro assessment of the physical properties of manually-mixed and encapsulated glass-ionomer cements. BDJ Open 2020;6:12.

3. Nomoto R, Komoriyama M, McCabe JF, Hirano S. Effect of mixing method on the porosity of encapsulated glass ionomer cement. Dent Mater 2004;20: 972-8.

4. Xie D, Brantley W, Culbertson B, Wang G. Mechanical properties and microstructures of glassionomer cements. Dent Mater 2000;16:129-38.

5. Bertenshaw BW, Piddock V. Porosity in water-based dental luting cements. J Mater Sci Mater Med 1993; 4:415-7.

6. McCabe JF, Ogden AR. The relationship between porosity, compressive fatigue limit and wear in composite resin restorative materials. Dent Mater 1987;3:9-12.

7. Barralet J, Gaunt T, Wright AJ, Gibson IR, Knowles JC. Effect of porosity reduction by compaction on compressive strength and microstructure of calcium phosphate cement. J Biomed Mater Res 2002;63:1-9.

8. Sulaiman TA, Abdulmajeed AA, Altitinchi A, Ahmed SN, Donovan TE. Effect of resin-modified glass ionomer cement dispensing/mixing methods on mechanical properties. Oper Dent 2018;43: E158-65.

9. Malkoç MA, Sevimay M, Tatar I, Çelik HH. MicroCT detection and characterization of porosity in luting cements. J Prosthodont 2015;24:553-61.

10. ISO Specifications 9917-1. Dentistry -Water-based cements- Part 1: Powder/liquid acid-base cements; 2007.

11. Al-Kadhim AHA, Abdullah H. Effect of Porosity on Compressive Strength of Resin Modified Glass Ionomer Luting Cements. IMJM 2018;17:33-40.

12. Milutinović-Nikolić AD, Medić VB, Vuković ZM. Porosity of different dental luting cements. Dent Mater 2007;23:674-8.
13. Billington RW, Williams JA, Pearson GJ. Variation in powder/liquid ratio of a restorative glassionomer cement used in dental practice. Br Dent J 1990;169:164-7.

14. Covey DA, Ewoldsen NO. Porosity in manually and machine mixed resin-modified glass ionomer cements. Oper Dent 2001;26:617-23.

15. Torres FFE, Guerreiro-Tanomaru JM, BossoMartelo R, Espir CG, Camilleri J, Tanomaru-Filho M. Solubility, porosity, dimensional and volumetric change of endodontic sealers. Braz Dent J 2019;30: 368-73.

16. Fleming GJ, Kenny SM, Barralet JE. The optimisation of the initial viscosity of an encapsulated glassionomer restorative following different mechanical mixing regimes. J Dent 2006;34:155-63.

17. Fleming GJ, Zala DM. An assessment of encapsulated versus hand-mixed glass ionomer restoratives. Oper Dent 2003;28:168-77.

18. Rupp D, Hermesch CB, Charlton DG. Effect of triturator speed variation on physical properties of encapsulated glass-ionomer luting cements. Oper Dent 1996;21:96-102.

19. Mount GJ. An atlas of glass-ionomer cements. A clinician's guide. London; Martin Dunitz; 2002. p. $1-42$. 


\title{
혼합방법에 따른 캡슐형 광중합글라스아이노머의 공극률 비교
}

\author{
김정민 전공의, 김진우 교수, 조경모 교수, 이윤 교수, 김응현 전공의, 박세희* 교수
}

강릉원주대학교 치과대학 치과보존학교실

목적: 본 연구의 목적은 혼합방법에 따른 여러 캡슐형 광중합글라스아이노머의 공극률을 비교 평가하는 것이다.

연구 재료 및 방법: 캡슐의 종류와 혼합방법을 달리하여 각각 5 개의 시편을 제작한다. 광중합글라스아이노머 캡슐로는 Photac Fil Quick Aplicap (PFQ), Fuji II LC CASULE (F2LC)을 사용하였다. 각 캡슐을 rotating 방식인 RotoMix와 shaking 방식인 CM-II로 혼합하였다. 각 시편의 무게와 높이, 반지름을 측정하여 밀도를 구하였다. 그 후 micro-computed tomography (micro-CT)로 스캔하여 시편의 장축을 따라 470 개의 단면을 얻은 뒤 $3 \mathrm{D}$ 로 재구성하여 각 시편의 공극 률을 측정하였다. 광중합글라스아이노머 캡슐의 종류와 혼합방법이 공극률에 미치는 영향을 평가하기 위하여 이원배치 분산분석(Two-way ANOVA)을 하였으며, 각 그룹에서의 유의성을 검증하기 위하여 $95 \%$ 유의수준에서 독립표본 $\mathrm{t}$ 검정 (Independent t-test)을 하였다.

결과: 광중합글라스아이노머 캡슐의 종류와 혼합 방법에 관계없이 모든 시편에 기포가 전반적으로 존재하였으며, 캡 슐의 종류와 혼합방법에 따른 공극률에 통계적으로 유의한 차이가 있었다. PFQ보다는 F2LC에서 공극률이 높았으며, Rotomix 보다는 CM-II에서 공극률이 높았다.

결론: 광중합글라스아이노머 캡슐의 사용 시에 광중합글라스아이노머 캡슐의 종류와 혼합방법에 따라 공극률에 유의한 차이가 있었다. 동일한 혼합기계를 사용할 때 $\mathrm{PFQ}$ 보다는 F2LC에서 공극률이 높으며, 동일한 캡슐을 사용할 때 Rotomix 보다는 CM-II에서 공극률이 높았다. RMGI 캡슐을 혼합할 때 같은 제조회사의 혼합기계를 선택하는 것이 더 적은 공극률을 유발하는 것은 아니므로 적절한 혼합기계의 선택을 하는 것이 중요하다.

(구강회복응용과학지 2021;37(4):217-24)

주요어:캡슐; 밀도; 마이크로시티; 혼합방법; 공극률; 광중합글라스아이노머

*교신저자: 박세희

(25457) 강원도 강릉시 죽헌길 7 강릉원주대학교 치과대학 치과보존학교실

Tel: 033-640-2760 | Fax: 033-640-3103 | E-mail: drendo@gwnu.ac. kr

|접수일: 2021년 10월 16일 | 수정일: 2021년 10월 29일 | 채택일: 2021년 11월 9일 